\title{
A case report of drug rash with eosinophilia and systemic symptoms syndrome induced by dapsone
}

\author{
Swathy A. R., A. N. Dattatri* \\ Department of Pharmacology, Karnataka Institute of Medical Science, Hubbali, Karnataka, India \\ Received: 26 December 2019 \\ Revised: 10 March 2020 \\ Accepted: 11 March 2020 \\ *Correspondence: \\ Dr. A. N. Dattatri, \\ Email: dattatri69@gmail.com
}

Copyright: ( $)$ the author(s), publisher and licensee Medip Academy. This is an open-access article distributed under the terms of the Creative Commons Attribution Non-Commercial License, which permits unrestricted non-commercial use, distribution, and reproduction in any medium, provided the original work is properly cited.

\begin{abstract}
Drug rash with eosinophilia and systemic symptoms (DRESS) syndrome is a distinct, severe, idiosyncratic reaction to a drug characterized by a prolonged latency period. It is followed by a variety of clinical manifestations, usually fever, rash, lymphadenopathy, eosinophilia, and a wide range of mild-to-severe systemic presentations. Among sulfonamides, Dapsone, sulfamethoxazole-trimethoprim and sulfasalazine are the most common offending drugs. We report here a case of DRESS syndrome due to dapsone.
\end{abstract}

Keywords: Dapsone, Dapsone hypersensitivity syndrome, DRESS syndrome

\section{INTRODUCTION}

According to $\mathrm{WHO}$, adverse drug reaction (ADR) is defined as any response to drug which is noxious or unintended and occurs at a dose normally used in man for prophylaxis, diagnosis or treatment of diseases or for modification of physiological function. ${ }^{1}$ ADRs may be said to be the inevitable price we pay for the benefits of modern drug therapy. Drug rash with eosinophilia and systemic symptoms (DRESS) syndrome is a lifethreatening disease with a mortality rate of around $10 \% .^{2}$ It is a severe hypersensitivity reaction to a medication or its reactive metabolites, which may be associated with enzymatic defects in drug metabolism. Aromatic anticonvulsants such as phenytoin, carbamazepine, and phenobarbitone and sulfonamides such as dapsone and sulfasalazine are the most frequently reported drugs causing DRESS. ${ }^{3}$ We report here a case of DRESS syndrome due to dapsone.

\section{CASE REPORT}

A 40-year-old male patient presented with chief complaint of dark patches over right forearm. Initially they were small in size and gradually progressed to involve the both upper limbs, chest, back and lower limbs over the course of 2 days.

The patient consulted a local doctor who diagnosed it as lichen planus and was treated with dapsone $100 \mathrm{mg}$ OD which patient took for 15 days. During the course of treatment, the patient developed fluid filled lesions on the lips, chest, abdomen, back, genitalia, upper and lower limbs. The lesions burst on application of pressure forming raw red areas in one day. The patient also complained of fever and throat pain.

Laboratory investigations included a total leucocyte count of $9500 \mathrm{cell} / \mathrm{mm}^{3}\left(3000-11000\right.$ cells $\left./ \mathrm{mm}^{3}\right)$, eosinophils $6.8 \%(2-3 \%)$, hemoglobin $10 \mathrm{~g} / \mathrm{dl}(12-16 \mathrm{~g} / \mathrm{dl})$, total protein $4.6 \mathrm{~g} / \mathrm{dl}(6-8 \mathrm{~g} / \mathrm{dl})$, albumin $1.5 \mathrm{~g} / \mathrm{dl}(3.5-5 \mathrm{~g} / \mathrm{dl})$, bilirubin $0.2 \mathrm{mg} / \mathrm{dl}(0.1-1.2 \mathrm{mg} / \mathrm{dl})$, AST- $26 \mathrm{U} / \mathrm{l}$ (upto 37 $\mathrm{U} / \mathrm{l}$ ), ALT $13 \mathrm{U} / \mathrm{l}$ (up to $40 \mathrm{U} / \mathrm{l}$ ), alkaline phosphatase 91 $\mathrm{U} / \mathrm{l}$ (40-170 U/l), urea $17 \mathrm{mg} / \mathrm{dl}(10-45 \mathrm{mg} / \mathrm{dl})$ and creatinine- $0.6 \mathrm{mg} / \mathrm{dl}(0.5-1.5 \mathrm{mg} / \mathrm{dl})$. 


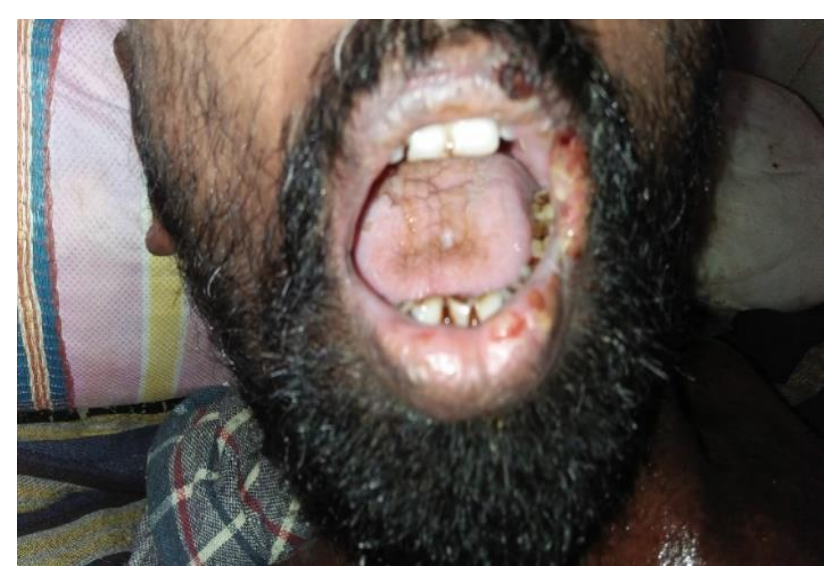

Figure 1: Cheilitis.

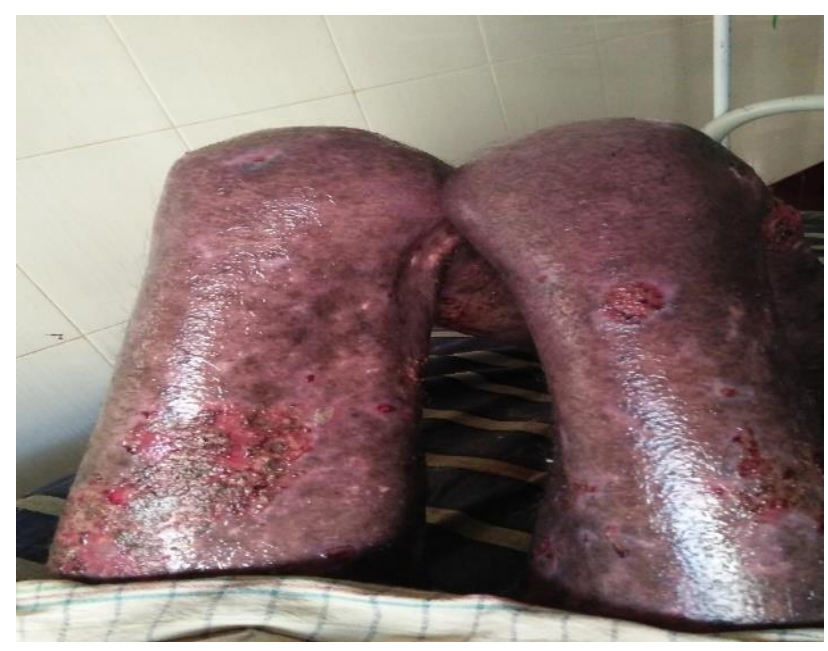

Figure 2: Erythroderma on thigh.

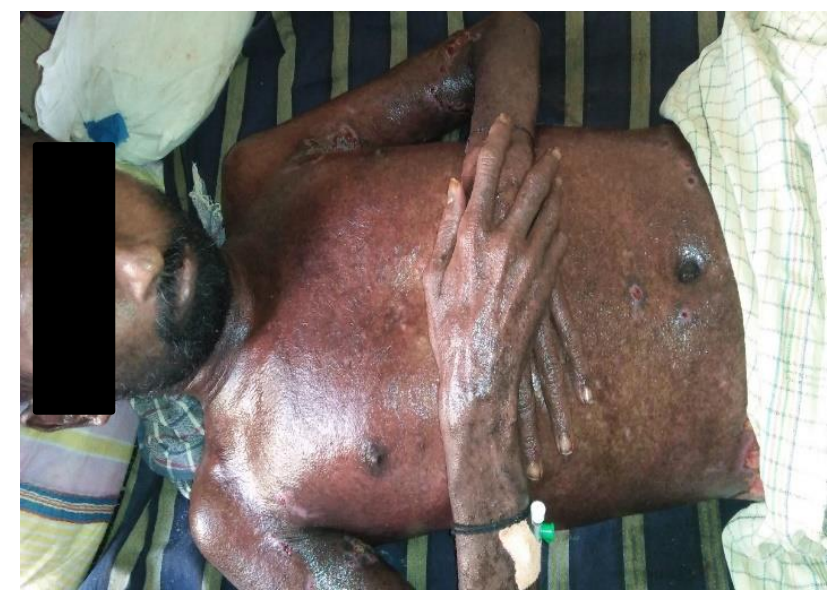

Figure 3: Maculopapular rashes on chest and abdomen.

\section{Diagnosis and management}

Patient was diagnosed to have DRESS syndrome induced by dapsone. He was treated in our hospital with piperacillin- tazobactam, metronidazole, paracetamol, triamcinolone, dexamethasone, IV fluids, chlorhexidine mouth wash, saline compression and pantoprazole.

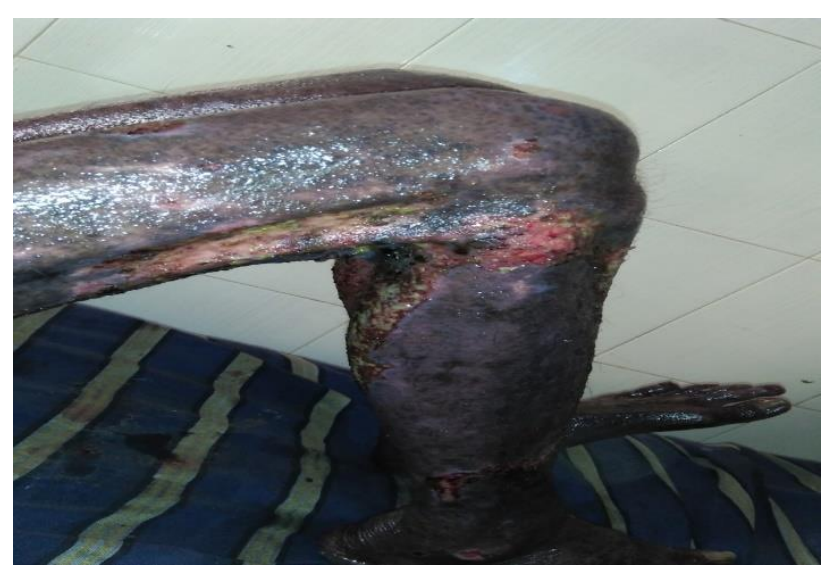

Figure 4: Pustules burst to form ulcer on thigh.

\section{DISCUSSION}

Dapsone Hypersensitivity Syndrome (DHS) is a rare dose-independent adverse effect reported with dapsone use in leprosy, malaria prophylaxis, dermatitis herpetiformis, lichen planus and various other conditions. DHS can develop several weeks to as long as six months after treatment initiation and the reported incidence ranges from $0.5 \%$ to $3 \%$. Manifestations of DHS include high grade fever, skin rash, lymphadenopathy, eosinophilia, hepatitis, acute pneumonitis, neurological and other systemic features of multi-organ dysfunction. The drug hypersensitivity syndrome associated with Drug Rash, Eosinophilia and Systemic Symptoms, as noted in the present case, is called DRESS syndrome. ${ }^{4}$ Common pharmacologic triggers for DRESS include aromatic anticonvulsants (mainly phenobarbital, phenytoin, and carbamazepine), antibiotics (mainly trimethoprimsulfamethoxazole, minocycline, vancomycin, and antitubercular drugs), dapsone, allopurinol and nevirapine. ${ }^{5}$ The aetiology of DRESS syndrome is not yet clear, but it has been suggested that this condition is multifactorial and may include an immune-mediated hypersensitivity component that is a direct effect of an interaction between the drugs or their metabolites and a genetic susceptibility. ${ }^{6}$ Furthermore, an interplay between drugs, viruses (mainly herpes virus 6 [HHV6], but also HHV7, Epstein-Barr virus and cytomegalovirus) and immune system may have a role as trigger of DRESS syndrome. ${ }^{7}$ Other clinical conditions, such as acute viral infections, hepatitis, sepsis, autoimmune disease, and haematologic disorders, should be considered in the differential diagnosis of DRESS syndrome.

The clinical manifestations are not immediate and usually appear 2 to 8 weeks after introduction of the triggering drug. ${ }^{8}$ Common features consist of fever, rash, lymphadenopathy, hematological findings (eosinophilia, leukocytosis, etc.), and abnormal liver function tests, which can mimic viral hepatitis. The cutaneous 
manifestations typically consist of an urticarial, maculopapular eruption and, in some instances, vesicles, bullae, pustules, purpura, target lesions, facial edema, cheilitis, and erythroderma. ${ }^{9}$ Visceral involvement (hepatitis, pneumonitis, myocarditis, pericarditis, nephritis, and colitis) is the major cause of morbidity and mortality in this syndrome. ${ }^{10}$ Many cases are associated with leukocytosis with eosinophilia $(90 \%)$.

Various authors have reported varying incidences of DRESS syndrome with dapsone. This case was diagnosed by correlating clinical symptoms and regiSCAR criteria for DRESS syndrome. Simrun et al reported a case of DRESS syndrome due to dapsone. ${ }^{11}$ Causality analysis using Naranjo's scale showed that phenytoin is the probable cause of the adverse reaction in present case (score=6).

DRESS syndrome is a life threatening condition and therefore supportive care is an essential part of the therapeutic approach. Prophylactic antibiotic use is recommended. The management involves prompt discontinuation of dapsone, systemic steroids (oral prednisolone $1 \mathrm{mg} / \mathrm{kg}$ per day or intravenous methylprednisolone in equivalent doses). Gradual tapering of prednisolone (over more than a month) is recommended considering the persistence of dapsone in the body up to 35 days. Mortality as high as $12-23 \%$ has been reported. Thus, a high index of suspicion for early diagnosis, along with prompt treatment are essential to prevent fatalities and late complication. ${ }^{12}$ In the present case however, the patient recovered well with the given treatment.

\section{CONCLUSION}

From this study it was concluded, knowledge of the past medical history of the patient regarding past drug allergy, family history of drug allergy or death in the family due to a drug is of great importance in order to avoid morbidity and mortality associated with hypersensivity to the drug. It is of utmost importance to be vigilant while administering drugs known to cause DRESS syndrome. Early diagnosis, identification of the culprit drug, its prompt withdrawal and specialized supportive care is the key to the management of a case of DRESS syndrome. Since dapsone is one of the commonest drug to cause DRESS syndrome, its use needs to be reconsidered in view of safer alternatives available.

\section{Funding: No funding sources \\ Conflict of interest: None declared \\ Ethical approval: Not required}

\section{REFERENCES}

1. Rohilla A, Yadav S. Adverse drug reaction: An overview. Int J Pharm Res. 2013;3(1):10-2.

2. Chen YC, Chiu HC, Chu CY. Drug reaction with eosinophilia and systemic symptoms. A retrospective study of 60 cases. Arch. Dermatol. 2010;146:1373-9.

3. Husain Z, Reddy BY, Schwartz RA. DRESS syndrome: Part I. Clinical perspectives. J Am Acad Dermatol. 2013;68:693.

4. Kosseifi SG, Guha B, Nassour DN, Chi DS, Krishnaswamy G. The Dapsone hypersensitivity syndrome revisited: A potentially fatal multisystem disorder with prominent hepatopulmonary manifestations. J Occup Med Toxicol. 2006;1:9.

5. Cacoub P, Musette P, Descamps V, Meyer O, Speirs C, Finzi L, et al. The DRESS syndrome: a literature review. Am J Med. 2011;124(7):588-97.

6. Besli GE, Yldrm S, Ylmaz K, Yuksel E. Drug reaction with eosinophilia and systemic symptoms syndrome or hematologic malignancy? A case report of a 4-year-old boy. Pediatr Emerg Care. 2017;33(7):494-6.

7. Marcus N, Smuel K, Almog M, Prais D, Straussberg $\mathrm{R}$, Landau D, et al. Successful intravenous immunoglobulin treatment in pediatric aevere DRESS syndrome. J Allerg Clin Immunol Pract. 2018;6(4):1238-42.

8. Rzany B, Correia O, Kelly JP, Naldi L, Auquier A, Stern R. Risk of Stevens-Johnson syndrome and toxic epider mal necrolysis during first weeks of antiepileptic therapy: a case-control study. Lancet. 1999;353(9171):2190-4.

9. Eshki M, Allanore L, Musette P, Milpied B, Grange A, Guillaume JC, et al. Twelve-year analysis of severe cases of drug reaction with eosinophilia and systemic symptoms: a cause of unpredictable multiorgan failure. Arch Dermatol. 2009;145(1):6772.

10. Chaudhary S, Macleod M, Torchia D, Romanelli P. Drug reaction with eosinophilia and systemic symptoms (DRESS) syndrome. J Clin Aesthet Dermatol. 2013;6(6):31-7.

11. Simrun D, Koteshwar K, Rajavardhan T, Bhavani M, Reddannal L, Sreedhar V. A case report on dapsone syndrome. Indian J Phar Pract. 2019:12(4):277-9.

12. Knowles SR, Shapiro LE, Shear NH. Reactive metabolites and adverse drug reactions: Clinical considerations. Clin Rev Allerg Immunol. 2003;24:229-38.

Cite this article as: Swathy AR, Dattatri AN. A case report of drug rash with eosinophilia and systemic symptoms syndrome induced by dapsone. Int J Basic Clin Pharmacol 2020;9:657-9. 